\title{
Making a Case for Change Management Theory to Support IS/IT Curriculum Innovation
}

\author{
Susan Benvenuti \\ University of the Witwatersrand, Johannesburg, South Africa
}

susan.benvenuti@wits.ac.za

\begin{abstract}
The complex and dynamic nature of the IS discipline and field poses an ongoing challenge for IS educators in terms of both what and how they teach. Responses to the curriculum challenge are many and varied, resulting in a diversity of approaches through which IS academics and educators attempt to manage the tension between current industry demands and good academic practice, while taking cognizance of the future developmental needs of IS graduates during their careers. Many of the curriculum innovations or pedagogical choices require significant changes to the teaching and learning environment for both student and teacher, resulting in programs or courses that, despite careful planning, sound pedagogical decisions and good intentions, do not fully deliver the desired or expected results. This work-in-progress paper explores the idea of adapting business change management and organizational development principles and frameworks to guide the curriculum design and implementation process. An undergraduate selfdirected learning experience provides the context for reflection and an experimental thinking ground.
\end{abstract}

Keywords: IS education, curriculum design and implementation, pedagogical change, change leadership, change management, organizational development, self-directed lifelong learning

\section{Introduction}

IS Educators are faced with the ongoing challenge of how to prepare future IS professionals for the complex and dynamic world in which they will work. With accelerating technological innovation, a growing number of new and diverse roles and career paths, and the need to manage the demands of the industry for ready knowledge and skills, IS educators draw on an increasingly broad set of pedagogical and assessment principles in order to meet these educational challenges.

In common with a growing number of disciples including medicine, engineering, law and education, IS educators are focusing on the development of IS graduates as self-directed lifelong learners during their formal education, in order that they may be able to successfully meet ongoing

Material published as part of this publication, either on-line or in print, is copyrighted by the Informing Science Institute. Permission to make digital or paper copy of part or all of these works for personal or classroom use is granted without fee provided that the copies are not made or distributed for profit or commercial advantage AND that copies 1) bear this notice in full and 2) give the full citation on the first page. It is permissible to abstract these works so long as credit is given. To copy in all other cases or to republish or to post on a server or to redistribute to lists requires specific permission and payment of a fee. Contact Publisher@InformingScience.org to request redistribution permission. professional development needs throughout their careers.

In response to the need to expose students to self-directed learning in order to start developing the skills, attitudes and abilities needed for successful lifelong learning, I devised a self-directed learning component as part of a $2^{\text {nd }}$ year systems development course. The reaction by some students to aspects of what I was trying to facilitate was unexpected, 
leaving me wondering how to best achieve some level of exposure to self-directed learning while dealing with their fear, resistance and in some cases apathy.

While reflecting on the reactions and behaviors of the students in response to the self-directed learning component, I was struck by the fact that this intervention was changing some fundamental aspects of the way students were used to working, as well as challenging the expectations traditionally linked to the role of student and lecturer. I felt therefore, that I was experiencing typical reactions to change. In this paper I present some work in progress in which I start experimenting with adapting established business change management principles, frameworks and approaches to meet the needs of substantial change in an educational setting.

The purpose of this work is to look to the substantial knowledge of the IS discipline in leading and managing organizational change together with organizational development to develop some frameworks which can be used in conjunction with pedagogic principles to guide and manage the design and implementation of curriculum innovations in IS/IT education.

\section{Background and Approach}

As the IS discipline continues to grow in scope, so too does the challenge to IS educators. Maier, Clark, and Remington (1998) explored changes in the IS job market over a period of fifteen years and found a growing diversity in IS roles and careers, with IS practitioners often expected to perform several of these roles during the course of their career, all of which have different requirements in terms of knowledge and skills. In addition, the work performed in the IS industry is frequently of a project type nature requiring IS professionals to constantly adapt to and learn about, new situations and new industries, depending on the requirements of each new project.

Curriculum development and review are frequently based on literature related to predicted workplace skill requirements (Noll \& Wilkins, 2002), or by working with industry advisors (Srinivasan, Guan, \& Wright, 1999). In IS 2010: Curriculum Guidelines for Undergraduate Degree Programs in Information Systems (Topi et al, 2010) suggest that this major revision in the curriculum guidelines is necessary due to the "rapid and frequent change" faced by the ever more global IS industry, leading to the need to re-evaluate what the core focus and outcomes of an IS degree should be.

Industry demands for students who not only have the 'required' knowledge but also the relevant skills creates further tension in the debate as to what balance is required between knowledge and skills, and the ongoing debate relating to an academic education versus a fit-for-work training. Kim, Shim and Yoon (1999, as cited in Noll \& Wilkins, 2002), report that practitioners and educators perceive the relative importance of key IS issues differently. Achieving a balance between IS fundamentals, and current trends and fads is a major dilemma in IS curriculum design according to Lightfoot (1999, as cited in Noll \& Wilkins, 2002). McMurtrey, Downey, Zeltmann, and Friedman (2008) confirmed previous findings that while IT professionals consider both technical and non-technical skills to be important for entry-level personnel, that the non-technical softskills are especially important for all IT positions, particularly for future learning and career advancement. They suggest that universities have a responsibility to ensure that new graduates are prepared from the start of their careers with skills that will allow success in careers in the continually changing IT industry.

The above debates notwithstanding, agreement on the need the need for IS graduates to be competent life-long learners is more easily reached. As Carl Rogers puts it, "We are in my view faced with an entirely new situation in education where the goal of education, if we are to survive, is the facilitation of change and learning" (Rogers, 1983). In common with the medical, engineering, legal and educational fields, IS education is starting to recognise both the truth and urgency of the following statement: 
"Short of a nuclear catastrophe, the growth of knowledge is not going to diminish enough to permit men and women to go confidently throughout their careers with the degree of mastery attained at the time of their professional certification; they will always need to continue to learn." (Houle, 1992, p. 224)

This view is shared by many others including Dublin (1988, as cited in Livneh, 1988, p 149), who estimated that rapid growth in technology and knowledge would render professionals in many fields only "half as competent as they were at graduation to meet the demands of their profession" ten to twelve years later, and Frandson who suggested that in some professions the 'half-life' of its knowledge might be as short as two to three years (1980, as cited in Livneh, 1988).

Ross and Ruhleder (1993, as cited in Turner, 2004) suggest that IS curricula should instil a sensitivity to change in social and organisational settings, and develop the ability to self-learn in an environment of rapid technological change.

So the need for IS graduates to be successful self-directed lifelong learners is gaining more widespread acceptance, while the debate around core curriculum, skills development and what pedagogical and assessment approaches best support these various imperatives, remains ongoing.

This paper discusses a small curriculum intervention that has been included as part of a second year, undergraduate course in systems development with the goal of exposing students to the process of self-directed learning. The introduction of this intervention raised some interesting reactions by many students that were very similar to those often experienced during organisational change initiatives. In studying the both the change management and organisational development (OD) literature as well as the curriculum development literature, little if any work looked at managing change in the educational environment in terms of the 'classroom' setting, i.e. in terms of curriculum, pedagogical or assessment change. Work has been done in terms of more institutional or global level educational change, where the change is like any other organisational change (either operational or strategic) but the educational setting becomes the specific context, but no work could be found that looked at the effect of introducing new pedagogical demands on the classroom participants.

This work in progress takes as a point of departure the idea that much of the change management or OD literature focuses on both the group (organisation) level and individual aspects of change, leadership of change initiatives, and resistance and readiness for change, and that these principles may well be of use in guiding any type of pedagogical change, not just the introduction of a selfdirected approach.

The research approach is an exploratory study in which the setting of the self-directed aspect of the $2^{\text {nd }}$ year course is used as a thinking space in which to explore and reflect on the idea of using change management principles and frameworks to guide curriculum planning and implementation. No empirical testing is done, but ideas are put forward for using adapted models, frameworks and theories for redesigning the self-directed learning aspect of the course for the next cohort of second year students.

\section{A Self-directed Learning Experience}

\section{A Brief Look at Self-directed Learning}

"Self-Directed Learning is that process in which individuals take the initiative, with or without the help of others, in diagnosing their learning needs, formulating learning goals, identifying human and material resources for learning, choosing and implementing learning strategies, and evaluating learning outcomes" (Knowles, 1975)The term "self-directed learning" however is used variously to describe two distinct aspects of self-directed learning; the first aspect relates to self- 
direction in terms of an approach, method or process, while the second aspect refers to selfdirection as a goal, product or outcome in terms of a learner's orientation. In addition, although suggestions are often made in this regard, very little evidence exists in terms of the relationship between self-directed learning as a process and a goal (Candy, 1991; Brockett \& Hiemstra, 1991; and others). Candy (1991) views the process method as consisting of two aspects; learner-control (self-direction) in an instructional situation as distinct from autodidaxy in a self-instructional situation. He also recognizes two aspects in the product view of self-direction; firstly that of selfmanagement in terms of a willingness and ability to undertake one's own education, and secondly that of self-determination which is strongly related to personal autonomy.

Self-directed learning is often linked with adult education (Brockett \& Hiemstra, 1991; Brookfield, 1985; Oddi, 1987, and many others). Brookfield argued against the assumption that all adults are by nature self-directed learners, with clearly and correctly defined "felt needs" and who simply need educators to facilitate learning in which these needs can be met. While he acknowledges the importance and role of the learner in determining what they wish to learn, he argues that educators have a responsibility to provide guidance and support to learners in determining their educational needs (Brookfield, 1985).

Grow (1991) concurs with this, observing that students possess different levels of ability with which to approach SDL situations. Basing his model on Hersey and Blanchard's Situational Leadership Model (1988, as cited in Grow, 1991), Grow put forward a Staged Self-Directed Learning (SSDL) Model which aims to actively equip students for SDL by identifying their current readiness for SDL and teaching accordingly. Readiness is defined as a combination of motivation and ability, and is also recognized as being potentially situational or task specific. Roles that teachers can play in facilitating learning with students of varying levels of self-direction are put forward by Pratt (1988), based too on situational leadership and its earlier influences. Grow uses self-directed learning in the context of his model to represent the degree of control that learners have over the learning situation, based on Candy's learner-control/teacher-control in formal education situations, summarized in Table 1.

Table 1: The Staged Self-Directed Learning Model (Grow, 1991)

\begin{tabular}{|c|l|l|l|}
\hline Stage & \multicolumn{1}{|c|}{ Student Readiness } & \multicolumn{1}{|c|}{ Ideal Teacher Role } & \multicolumn{1}{|c|}{ Examples } \\
\hline 1 & $\begin{array}{l}\text { Dependent }- \\
\text { low self-direction }\end{array}$ & Authority, Expert, Coach & $\begin{array}{l}\text { Informational lectures } \\
\text { Immediate feedback }\end{array}$ \\
\hline 2 & $\begin{array}{l}\text { Interested }- \\
\text { moderate self-direction }\end{array}$ & Motivator, Guide & $\begin{array}{l}\text { Inspirational lectures } \\
\text { Guided discussion } \\
\text { Goal setting, learning strategies }\end{array}$ \\
\hline 3 & $\begin{array}{l}\text { Involved }- \\
\text { intermediate self-direction }\end{array}$ & Facilitator & $\begin{array}{l}\text { Facilitated discussion } \\
\text { Seminars } \\
\text { Group projects }\end{array}$ \\
\hline 4 & $\begin{array}{l}\text { Self-directed }- \\
\text { high self-direction }\end{array}$ & Consultant, Delegator & $\begin{array}{l}\text { Dissertation } \\
\text { Internship } \\
\text { Individual work } \\
\text { Self-directed study group }\end{array}$ \\
\hline
\end{tabular}

For Grow, the teacher's purpose is to match their role, teaching style and approach to the level of student readiness for self-directed learning. In a similar way to the situational leadership model, students should gradually develop towards a higher degree of self-directedness. 
Grow does however recognize that a student's level of self-directedness is unlikely to be the same across all learning situations. Some features of self-directedness relate to things like motivation, prior knowledge, experience or ability, which might vary considerably across subjects or areas of endeavor for any particular student. Others like persistence or confidence are more personality traits and are likely to be consistent at a particular point in time.

Although the SSDL model is designed with progression through the various levels in mind, Grow acknowledges that the progress of both individual students and classes is unlikely to always be linear, and that any class is likely to have a mix of levels of SDL readiness amongst the students. This led to the conceptualization of the non-linear iterative SSDL in which a course or program is organized around one particular level but draws on other levels as appropriate.

\section{Designing the Self-directed Learning Experience}

When designing the self-directed learning experience, the focus in terms of SDL was on developing an awareness of the need for self-directed learning skills for ongoing professional development, as well as developing some of the skills necessary in undertaking a self-directed learning project.

The students in question at the start of their second year of study are young "soon-to-be" adult learners and therefore do not as yet necessarily display the typical characteristics of adult learners such as felt needs, self-direction, voluntary participation, critical reflection, etc (Brookfield, 1985). In particular, as students in a formal educational setting with little or no real experience, they do not as yet have "perceived needs" or gaps in their knowledge and skills that they are aware of, that could be pursued through a SDL-based course. In fact many students question the relevance of some courses taken in their degree or IS major in terms of their future careers. The SDL-based experience therefore created a situation in which students have to identify gaps in their knowledge and skills and plan to work towards closing some selected gaps.

Using Grow's Staged Self-Directed Model as a guide, the SDL experience was organised around the Stage 2 (Moderate) level of self-direction applying the non-linear, iterative approach (Grow, 1991). At this stage, learners are described by Grow to be "available", "interested or interestable", and will respond to motivation and tasks that they view as being worthwhile. The teacher at this stage should bring excitement, enthusiasm and motivation to the classroom, selling the importance of the knowledge and skills, providing support and personal interaction. Goal setting and various learning strategies are used at this level.

The non-linear, iterative approach recognises that regardless of their stage of self-direction, learners might need higher or lower levels of support in some aspects or areas and makes allowances for this as shown in figure 1.

As students are helped to progress towards the stage 3 level of self-directedness, goal setting and a movement away from extrinsic motivation (praise giving) toward more intrinsic motivation using encouragement and support is appropriate. Students should begin to develop a deeper sense of themselves including their goals, personality type and preferred learning styles (Grow, 1991). 


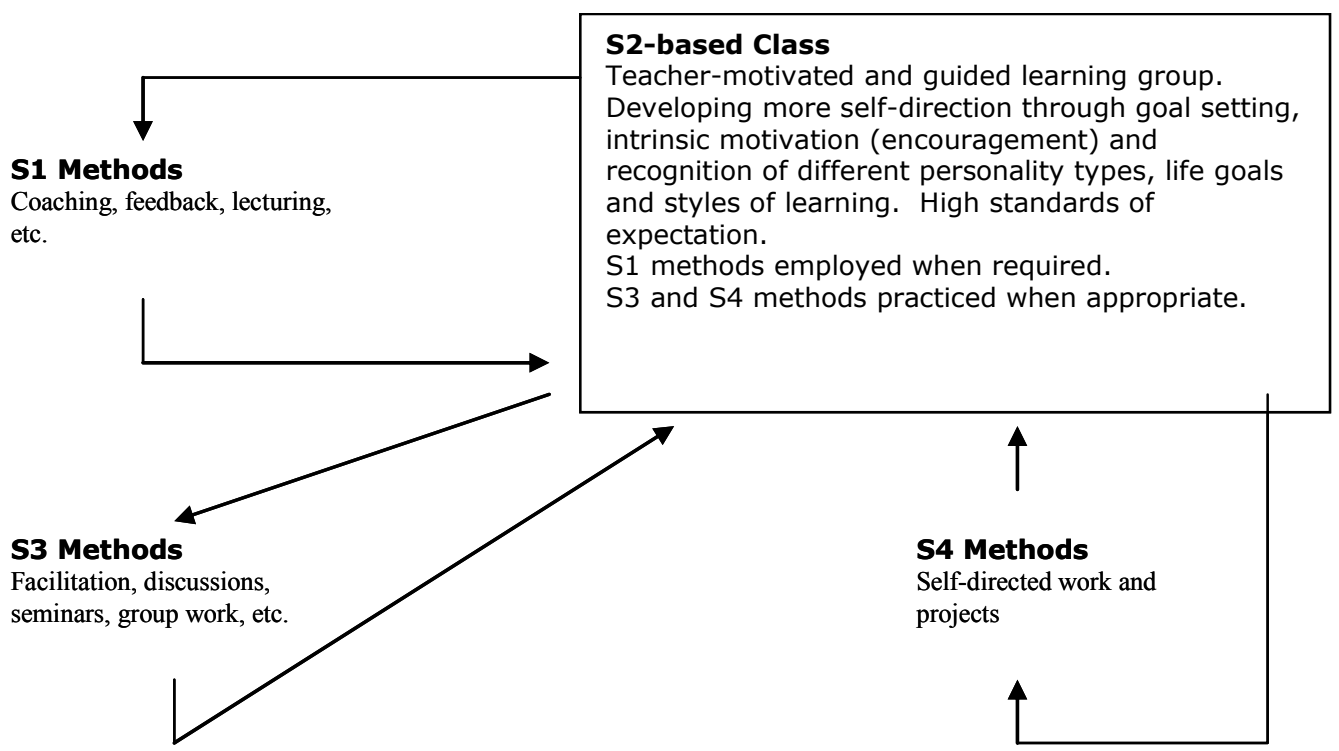

Figure 1: A Stage 2 based class - Adapted from The Staged Self-Directed Learning Model Non-linear, Iterative Approach (Grow, 1991)

\section{The Personal Development Portfolio - A Self-directed Learning Experience}

The SDL experience was conceptualized around a Personal Development Portfolio (PDP) in which students are challenged to start developing a professional identity. Students were working on a case study based Systems Analysis and Design project at the same time in self selected teams of four or five students. The focus of the portfolio was given as follows:

\footnotetext{
As you begin your $2^{\text {nd }}$ year of IS study, you go beyond a general understanding of the discipline and start to explore the world of work of IS professionals, and work towards developing the knowledge, skills, attitudes and attributes needed for success in IS careers.
}

As you will begin to see, there are a multitude of different roles, careers and working environments in which IS professionals work, and over time you can expect to move within these and require new knowledge, skills etc. in order to succeed.

Our focus in the Portfolio of this project is to allow you to focus on your emerging IS Professional Identity to think about your particular career aspirations and to focus on developing yourself towards these goals. I hope that you will find this a rewarding and enlightening experience.

The overall design of the PDP was aimed at Stage 2 of Grow's SSDP with supporting class activities and the team project drawing on stage 1 and 3 approaches.

The Personal Development Portfolio was completed over the first semester of the second year of study, with 3 submissions occurring at the start, towards the middle and near the end of the semester. The first submission entailed analyzing, selecting and planning for some self-directed learning; the second required students to reflect on their learning to-date and make any amendments to their proposed learning goals; and the third was a report back on their learning and a reflection on their achievements.

In the first submission, students were asked to do the following:

1. Ideal Job Profile - students needed to find an advert for their dream job and using the advertised criteria and research on similar positions to draw up a profile of the knowledge, skills, experience, attributes, interests, attitudes, etc. that an ideal candidate for the position would possess. 
2. Personal Analysis - students were then asked to position themselves against the required criteria they had identified for their dream job using a SWOT analysis.

3. Personal Development Plan - thereafter, students drew up a development plan for the first half of the year that focusing on two or three aspects of the knowledge, skills, values, etc. that they would need to acquire or develop prior to landing their dream job. The goals should be focused, manageable, and achievable, working towards a sense of development, growth and achievement. Students were told that they were not necessarily expected to reach the final point for a goal, but to make some progress towards it.

4. Reflective Review - finally, students were asked to keep a learning journal that should serve both to record and report on work towards their goals and reflect on their progress, successes, difficulties, etc. The journal could then be used as a resource for writing a brief reflective review for each of their three submissions. The reflective review for their first submission asked them to write about their feelings relating to this portfolio with guiding questions.

The two subsequent submissions required students to report on progress against their learning contract or plan, and to write a reflective piece; in the first case on a critical learning incident relating to their learning goals, and in the final submission relating to their overall experience engaging with the SDL portfolio.

\section{Evaluating the Self-directed Learning Experience}

Looking back at the response to the PDP self-directed learning experience, many interesting reactions emerged. Many students began by embracing the idea as we discussed the PDP in class. However as some of the details emerged a few students began to display signs of and verbalize their unhappiness with the requirements. Comments like "Why should we have to do this?", "I can't (won't) keep a learning journal", "this is a waste of time - what does it have to do with IS?" emerged.

The majority of students however seemed open to the idea, and it was only as the date for submission approached that they started to show fear, anxiety and resistance to the idea. Their comments related to issues around lack of knowledge about how to do this - "but how can we decide what to learn or how to learn", inability to write, too much work to do, and relevance to their work right now. Others resented the lack of very clear guidance.

When reading and assessing their early submissions I found huge differences within the quality of work submitted by the students. Some students had failed to follow the guidelines, both the written requirements and the subsequent class discussions. Others had done pieces of the work but it lacked completeness and coherence. Some pieces of work were good to very good, but seemed still to be accompanied by comments in their reflective writing that showed that they were unhappy or resentful of the task they had been given.

A few students, and interestingly, not always the expected high achievers managed the first task well and began the work with a positive energy and enthusiasm, displaying abilities that hadn't come through in previous work.

Over the course of the semester, the vast majority of students improved their submissions considerably and as they gained confidence in what they were doing, seemed more able to pursue their learning goals and reflect readily and with a fair degree of openness and self-awareness on what they were achieving.

As the course leader, I was frustrated by the fact that it took so long for students to see the value in what I was trying to achieve, thereby causing them unnecessary anxiety and limiting what they 
were able to achieve in the short time available. Furthermore, some students never seemed to reach the point of accepting the challenge and making the effort to try to achieve something.

In pondering the above I was struck by the fact that students essentially appeared to simply be reacting to change in many of the usual ways: fear and anxiety, resistance, apathy and sabotage. I therefore began looking at the literature for guidance that would enable me to design and implementation an SDL experience with using an appropriate approach.

\section{Managing the Changing Educational Environment}

\section{Change Management and Organizational Development}

Organisational change seems inevitable today, regardless of the extent to which organisations are ready to deal with it (By, 2007). Increased competition and the need for strategic flexibility and adaptability brought on by globalisation, is affecting almost every organisation today, regardless of size, market, focus, etc. (Jaros, 2010). These changes occur across the spectrum and include strategic, structural, operational, process and cultural change (Armenakis, Harris, \& Mossholder, 1993). Managing organisational change successfully therefore remains one of the most important focuses of all levels of management, just as embracing and surviving change is important to all employees. Change initiatives however are far from easily accomplished, with Balogun and Hailey (2004) reporting that approximately $70 \%$ of initiatives are not completely successful.

Change albeit in an organisational setting is an intensely personal experience. Duck (1993) claims that in order for significant change to occur in any organisation, each person within that setting must undergo a change, in terms of their thoughts, attitudes or actions. Reaction to change is often associated with similar emotions to those experienced with loss and grief (Carr, 2001; Elrod II \& Tippett, 2002). Strickland (2000, as cited in van Schoor, 2003) identifies these as being of loss of identity, in which the setting of a job or role changes; loss of belonging, in which teams or relationships are broken, or loss of meaning in which long held occupational values are changed. Loss of mastery (Moran \& Brightman, 2001) is experienced when the change is such that new skills have to be learned in order to continue to perform as before.

Trader-Leigh (2002) identifies specific factors that contribute to resistance to change including self interest, in which the change is seen to negatively impact on the person in some way, psychological impact, in which the change is perceived to threaten expertise and social status in the organization, and the redistributive factor, in which the redistribution of tasks and responsibilities might directly affect the person.

Change is viewed by many as difficult; difficult to conceive and difficult to implement, not least because of the people issues involved (Carnall, 2003). Change management seeks to employ formal strategies to counter the organisational and people issues encountered in times of change. In particular, resistance to change receives much attention. Carnall (2003) argues that what is referred to as resistance to change could be better explained as resistance to uncertainty. Armenakis et al (1993) suggest that an organisation's readiness for change can be seen in the beliefs, attitudes, and intentions of employees relating to the perceptions of the extent to which the change is needed, and the capacity of the organisation to achieve it. Furthermore, they suggest that "readiness is the cognitive precursor to the behaviours of either resistance to, or support for, a change effort" (Armenakis et al., 1993, pp 681-2). Jones et al. (2005, p 362, as cited in By, 2007), describe readiness as reflected in "positive views about the need for organisational change (i.e. change acceptance)", together with the belief that the change will benefit both themselves and the organisation. 
Armenakis et al (1993) state that while many researchers have discussed the importance of creating readiness in change management initiatives, readiness is most often treated together with resistance as a means by which to reduce resistance thereby increasing the potential for successful change initiative. They argue that by viewing readiness as separate from resistance, a more proactive and positive change management approach is likely.

Organisational change has been conceived of as having many dimensions requiring consideration during the process. These include the nature of the change, the end result, roles, styles, timing, scope, capacity, capability, readiness, etc. These in turn have led to various definitions of principles of change management, and methods or approaches to leading organisational change initiatives.

Armenakis et al (1993), Armenakis and Harris (2002), Jones et al (2005), Kotter (1996) and others, all recommend that organisations seek to establish a degree of change readiness before embarking on any organisational change. Armenakis et al (1993), Armenakis and Harris (2002), propose using a change message to create readiness, defining five key message components and three conveying strategies as shown in Table 2.

Table 2: The Change Message (By, 2007; adapted from Armenakis et al (1993), Armenakis and Harris (2002))

\begin{tabular}{|l|l|}
\hline \multicolumn{1}{|c|}{ Key message components } & \multicolumn{1}{c|}{ Message conveying strategies } \\
\hline $\begin{array}{l}\text { Discrepancy (is change really necessary?) } \\
\text { Efficacy (can this change be implemented successfully?) }\end{array}$ & $\begin{array}{l}\text { Persuasive communication (direct communication, e.g. } \\
\text { speeches and memos) }\end{array}$ \\
$\begin{array}{l}\text { Appropriateness (is this the change required?) } \\
\text { Active participation (vicarious learning and participa- } \\
\text { to this change?) }\end{array}$ & $\begin{array}{l}\text { tion in decision making) } \\
\text { Personal valence (what is in it for me?) }\end{array}$ \\
the views of others, e.g. consultants)
\end{tabular}

Kotter (1995), still recognised as one of the leading experts in the field of change management, proposes "Eight Steps to Transforming Your Organisation", while Kanter et al's (1992) “Ten Commandments for Executing Change" can be linked to many of the readiness factors.

Strebel (1996) recommends incorporating "revision of personal compacts" in the process in order to deal with uncertainty and resistance. The "personal compact" is defined by Strebel as the "mutual obligations and commitments that exist between employees and the company", both formally and implicitly. The personal compact is seen as defining an employees' view of their responsibilities, level of commitment to their work, and the values held by the company, in terms of three dimensions: formal, social and psychological. Similarly, Maguire's psychological contract (2002, as cited in van Schoor, 2003) suggests the need for a balance between the demands made by an organisation on its employees' skills, knowledge and experience, and the way in which organisations recognise the needs and values of its people. When change occurs, lack of attention to existing personal compacts may result in perceptions of breach of trust, as employees face an unpredictable future and uncertainty in terms of their role and capability in the new order. It is therefore vital that leadership formally revise personal compacts in times of change (Strebel, 1996).

The role of the change agent or leader also receives a fair amount of attention in the change management literature (Higgs \& Rowland, 2010) with research including the role of leadership in change management success and how leader beliefs can influence their choices in approaches to change management and its implementation. Higgs and Rowland examined leadership behaviors on change success in differing contexts, identifying three broad sets of leadership behavior, mindsets and practices (2010). Shaping Change was defined as a leader-centric approach in which the 
leader controls what is done; Framing Change focuses creating a framework through which contribution to change by others is possible; and Creating Capacity enables change through individual and organization capability, encouraging growth and learning.

\section{Identifying the Appropriate Frameworks and Guiding Principles}

While much of the change management literature deals with organisational change, the changes being made to the students' learning environment are very similar to organisational change in terms of the demands they make on the students, and the effect and reactions that they might be expected to produce.

Firstly, lecturers are likely to perceive the changed learning environment in a very different way to the students. While lecturers introduce pedagogical change in response to perceived needs and benefits, students are unlikely to welcome a change which takes them out of their comfortable and familiar approach to learning, and imposes new, unfamiliar demands on them, in the same way as Strebel's (1996) employees view change as disruptive and unwelcome as it removes the stability of their world, Similarly, as employees feel that their "personal compacts" with the company and management have been changed, so students may well feel that their relationship with the educational institution and staff has changed. Uncertainty in terms of roles, responsibilities, support, assessment and evaluation, effort and reward, might emerge.

Secondly, a radical change in the design of a course can be viewed as very similar to radical change in the way an organisation does business. Organisational change can include changes in terms of business processes, products or services, the market it serves, the way it interacts with customers or suppliers, etc. In the same way, the change from a traditional, lecturer driven course to a self-directed learning experience brings new processes, different outcomes or products, serves a different market (self-directed, adult learners) and interacts with the students in a very different way.

The students were clearly anxious about how they would cope within this new educational setting, which was in many respects unpredictable in terms of its demands, and for which they felt unprepared and inexperienced. For many of them, the academic world had turned upside down. They were being asked to decide what they needed to learn, how to go about learning it, to assess their achievement and decide how to demonstrate or provide evidence of their achievement. In essence, their accepted view of how things should work had been violated, and an unwritten agreement broken.

Starke, Sharma, Mauws, Dyck, and Dass suggest a "growing consensus that successful implementation of transformational change requires an emphasis on both leadership (the social/emotional /relational aspects of change) and management (the technical/instrumental/task aspects of change)" (2011, pg 30). With this in mind, it makes sense to use a two-pronged approach to identifying and adapting appropriate frameworks and principles to support the pedagogical change initiative; firstly those that will enhance the leadership aspect of the lecturer's (change agent's) role and secondly those that will allow for the management of the process.

\section{Leadership of change}

Successful leadership of change implies ensuring that the social, emotional and relational concerns of those directly affected by change are considered and made provision for, by the change agent (Starke, Sharma, Mauws, Dyck, \& Dass, 2011).

"One of the paradoxes of change is that trust is the hardest to establish when you need it most" (Duck, 1993, p 69). She further suggests that trust during change relies on "predictability and capability" (1993, p 70). Strebel's (1996) approach of explicitly acknowledging the change in the preexisting albeit unwritten or unspoken personal compact between student and lecturer, might 
therefore be useful in achieving student buy-in to the new learning approach, as trust between lecturer and student must be established and maintained in order to facilitate a successful transition into the new learning environment (Duck, 1993).

Taking cognisance of Carnall's (2003) view that change is seen as difficult due in large part to the people related issues, I began by looking at the issues that had emerged during the early stages of the SDL experience, and many of them seemed related to a either real or perceived fears that the students held, around their ability to do what was being asked of them. In other words many of them seemed to believe that they were not ready to engage with or perform the tasks needed for the SDL experience. The other set of reactions seemed to link to motivation, with students either not seeing the value in what they were being asked to do, or not being prepared to put in the effort required to achieve the results.

Both the motivation and abilities could be clearly linked to issues raised with regard to readiness for change and highlighted for me the need to think about how to begin the SDL experience by first attempting to ensure readiness for change before expecting students to embark on the experience itself.

Duck (1993) claims that in order for significant change to occur in any organisation, each person within that setting must undergo a change, in terms of their thoughts, attitudes or actions. Having considered the early response to the SDL experience I realised that the first change was required of me - as change leader or facilitator. The challenge is to understand what type of change I am leading, what type of shift I am expecting from the students, and how I can blend the role of change leader or facilitator with the type of teaching role needed for Grow's Stage 2 SSDL model.

Considering that Grow's SSDL model requires the dominant teaching role to be that of motivator and guide, with the stage 1 role of coach and authority and stage 3 role of facilitator also coming in to play, the most useful leadership behaviour to adopt when leading change in this situation appears to be that of framing change in which the leader creates a framework for contribution to and participation in the change. This involves a high level of trust in the participants, as well as creating and selling the vision, direction and need for change (Higgs \& Rowland, 2010). The capacity creating leadership approach which focuses on developing people's skills relating to change, providing feedback on progress, and providing coaching for improvement (Higgs \& Rowland, 2010) might also prove useful in supporting the stage 1 SSDL type leadership role.

Armenakis et al (1993, p. 682) suggest that "framing a project in terms of readiness seems more congruent with the image of proactive managers who play the roles of coaches and champions of change". Crafting a change message that conveys the five message components of discrepancy, efficacy, appropriateness, principal support and personal valence via the message conveying strategies of persuasive communication, active participation and managing information ties in with the framing approach to change leadership of Higgs and Rowland (2010), would allow for a focused and complete communication to be put across to students prior to and during the SDL experience. The messages can convey much of what is said or implied already in the course notes, PDP requirements, etc., but carefully crafted and intentionally delivered could provide a more powerful and compelling message. They do however caution that this strategy relies on the expertise, trustworthiness, credibility and sincerity of the change agent (Armenakis et al, 1993) further supporting Duck's view on developing trust between change leaders and participants (1993). Acknowledgement of Strebel's (1996) personal compact, and the changes being made to it, could also form part of the change message. 


\section{Managing the change}

Potgieter and Bruce-Ferguson (2003) suggest that top down change in educational institutions which is typically delegated to heads of departments, untrained in change management and not tasked with it in their formal job descriptions, should draw on action research together with organisation change management approaches. As action research is frequently used to drive, manage and evaluate educational innovation it makes sense to include it as part of the change management approach in this situation too.

Of use in guiding the work towards both readiness for change and actually managing the change process, could be an adapted version of Kotter's (1995) "Eight Step Model for Transforming Your Organisation", a summary of which is set out in table 3. This model could also provide guidance for the on-going redesign of the actual SDL experience, as well as for suggesting where supportive in-class exercises could be designed and implemented.

Table 3: Kotter's (1995) “Eight Step Model for Transforming Your Organisation

\begin{tabular}{|c|l|}
\hline 1. & Establishing a Sense of Urgency \\
\hline 2. & Forming a Powerful Guiding Coalition \\
\hline 3. & Creating a Vision \\
\hline 4. & Communicating the Vision \\
\hline 5. & Empowering Others to Act on the Vision \\
\hline 6. & Planning for and Creating Short-Term Wins \\
\hline 7. & Consolidating Improvements and Producing Still More Change \\
\hline 8. & Institutionalising New Approaches \\
\hline
\end{tabular}

Kanter et al's (1992) "Ten Commandments for Executing Change" shown in table 4 would provide similar input and guidance to both the process of designing and managing the SDL experience, as well as supporting to move towards readiness.

Table 4: Kanter et al's (1992) “Ten Commandments for Executing Change”

\begin{tabular}{|l|l|}
\hline 1. & Analyze the organization and its need for a change \\
\hline 2. & Create a shared vision and common direction \\
\hline 3. & Separate from the past \\
\hline 4. & Create a sense of urgency \\
\hline 5. & Support a strong leader role \\
\hline 6. & Line up political sponsorship \\
\hline 7. & Craft an implementation plan \\
\hline 8. & Develop enabling structures \\
\hline 9. & Communicate, involve people, and be honest \\
\hline 10. & Reinforce and institutionalize the change \\
\hline
\end{tabular}


While essentially aiming for similar outcomes and in many instances overlapping, the above two models have slightly different emphases and starting points. In adapting and applying the models I draw from each at different points to add to and support an overall leadership and change framework suitable to my needs as change agent. Furthermore, aspects of the models are not necessarily suitable as is, as we are not working with an organisation but with a cohort of students who will move through the course and on to other courses. Therefore steps that focus on institutionalising the approaches or changes need to be reconceived in terms of the individual.

\section{Adapting and Applying the Appropriate Leadership and Management Principles}

The $2^{\text {nd }}$ year course currently starts off with an introductory lecture in which all aspects of the course are explained. This introductory talk explains the overall focus of the course (systems analysis, design and implementation) and positions it in relationship to previous courses as well as future courses at higher levels. The interactive nature of the workshop based teaching is introduced, together with the idea of the course long, team-based systems development project which is used as both a teaching and assessment vehicle. At this point students are also told about the SDL aspect of the project and how it relates to the roles that they will play in the project and in their future careers.

This means that in the past, readiness for change was assumed to be possible by communicating the need or discrepancy using persuasive argument (By, 2007) and suggesting an urgency for change (Kanter 1992; Kotter, 1995). No opportunity was given for active participation (By, 2007 ) in discovering the discrepancy by analyzing the situation and the need for change (Kanter, 1992). Thereafter the change message as put forward by the lecturer suggested that efficiency, appropriateness and support should all be taken as agreed and necessary (By, 2007) and the assumption was that the students would simply buy in to the shared vision (Kanter 1992; Kotter, 1995) and develop the necessary skills and confidence to tackle the SDL task. Furthermore it was assumed that in completing the PDP students would come to realize the personal valence in the task (By, 2007) and be able to consolidate and produce more change in the future as it became part of their internalized approach to learning (Kanter 1992; Kotter, 1995).

The challenge therefore is to develop a comprehensive plan through which to communicate the five components of the change message, using a mix of the three strategies of persuasive communication, active participation and managing information in order to create a climate of readiness for change (Armenakis et al, 1993; By, 2007). A possible strategy would involve embarking on the early aspects of the course which involve examining the context of systems development and the roles which IS professionals play in the process.

An guided active learning session in which project teams analyse the knowledge, skills and values required by the various members of a typical project development team (business analysts, systems analysts, project managers and technical specialists) using real recruitment adverts would allow students to identify many of the required skills, knowledge and values for themselves. Team or class discussions could then explore how IS professionals might go about acquiring these skills and could help to develop a sense of the discrepancy. Using outside consultants (the third message conveying strategy) early on in the course (instead of towards the end as is currently the case) to discuss IS careers and career development, would help towards meeting some of the initial steps in Kotter and Kanter's models including:

- Realizing and analyzing the need for change (Kanter: step 1)

- Creating a shared vision of what is needed (Kanter: step 2; Kotter step 3)

- Establishing a Sense of Urgency(Kotter step 1; Kanter step 4) 
Thereafter, the PDP can be introduced and put forward as a means by which to "Empower" the students to "Act on the Vision" (Kotter's $5^{\text {th }}$ step). At this point, the $5^{\text {th }}$ aspect of the change message (By, 2007), personal valence, should have been conveyed and accepted by the students.

Using work teams with students who share similar development goals, implementation plans can be crafted (Kanter's $7^{\text {th }}$ step) and enabling structures (Kanter's $8^{\text {th }}$ step) of peer and lecturer support put in place. This should help to communicate the efficiency, appropriateness and support aspects of the change message (By, 2007) using active participation as the strategy rather than simply persuasive communication.

Providing supportive feedback through early formative assessment of the PDP can be used to "Create Short Term Wins" (Kotter - step 6) and will also go some towards ensuring that Kanter's $9^{\text {th }}$ step "Communicate, involve people, and be honest" is fulfilled. Thereafter, the completion of a Critical Incident Report as part of the $2^{\text {nd }}$ submission should assist students in "Consolidating Improvements and Producing Still More Change" (Kotter - step 7) as they are led through a reflective process that helps them to identify and recognise progress towards their goals.

Ongoing reflective writing and the chance to demonstrate evidence of their progress towards their initial learning goals in their final submission, together with supportive feedback from the lecturer should help to demonstrate their ability to conduct self-directed learning initiatives and to consolidate a sense of ownership in their career development. With a heightened awareness of how the various aspects of their degree and formal learning are structured to meet industry requirements as discovered through their PDP, a deeper and more personal commitment to their further development should also be evident.

Using the above more considered and structured approach to the self-directed learning experience, drawing on concrete leadership and management of change guidelines will hopefully result in an earlier uptake of the SDL experience by students and an overall more satisfactory and sustainable result. However, as Potgieter and Bruce-Ferguson (2003) suggest, managing change in an educational environment should also include a strong element of action research allowing for an ongoing refinement of the approach.

\section{Conclusion - The Way Forward}

In this paper, the possibility of using organizational change management principles to support the design and implementation of curriculum innovations in circumstances where significant change is introduced into the educational environment is explored, focusing on the role of the change agent (lecturer) to lead and manage throughout the process. The interest in exploring this possibility was born out of frustrations and setbacks encountered in introducing a self-directed learning experience into an undergraduate IS course which fundamentally changed the learning environment and expectations of the students.

Concepts such as readiness for change, resistance, and leadership in change management were looked at, with the goal of identifying principles and frameworks that could be used in conjunction with Grow's (1991) Staged Self-Directed Learning Model to develop and facilitate selfdirectedness in students.

As this paper reports on a piece of work in progress, no empirical testing has been done so no conclusions can be drawn. However, some ideas have been drawn from the literature on change management, and put forward for using various principles and frameworks in the redesign of the SDL experience. Using Potgieter and Bruce-Ferguson's view of change leader as action researcher (2003), results on testing these ideas with the next cohort of students will be reported on at a later date. 
Furthermore, it is hoped that these and other change management principles can be used in other curriculum design situations where change in the educational environment is sufficiently great to cause potential resistance and threaten the success of students or the desired educational outcomes. Situations such as the change in expectations as students enter tertiary education for the first time, for example, might be better understood and managed in the light of change management theory, instead of resorting to standard explanations such as student deficit. The introduction of an authentic learning experience with its purposeful lack of criteria and problem definition, or helping students to come to terms with active learning or collaborative, team based work are the types of interventions in which student resistance occurs (White, Pinnegar \& Esplin, 2010) and which spring to mind as potential areas of related research.

So much careful analysis, planning, design and development goes into the implementation pedagogical innovations that it seems unfortunate that we don't try to mediate the potential risk of failure due to change.

\section{References}

Armenakis, A. A., Harris, S. G., \& Mossholder, K. W. (1993). Creating readiness for organizational change. Human Relations, 46(6), 681-703.

Balogun, J., \& Hailey, V. H. (2004). Exploring strategic change (2nd ed.). Harlow: Pearson Education.

Brockett, R. G., \& Hiemstra, R. (1991). Self-direction in adult learning: Perspectives on theory, approach and practice. London and New York: Routledge.

Brookfield, S. (1985). A critical definition of adult education. Adult Education Quarterly, 36(1), 44-49.

By, R. T. (2007). Ready or not ... Journal of Change Management, 7(1), 3-11.

Candy, P. C. (1991). Self-direction for lifelong learning. San Francisco: Jossey-Bass.

Carnall, C. A. (2003). Managing change in organisations (4th ed.). Harlow: Pearson Education.

Carr, A. (2001). Understanding emotion and emotionality in the process of change. Journal of Organizational Change Management, 14(5), 421-436.

Duck, J. (1993). Managing change: The art of balancing. Harvard Business Review. November-December. Boston: Harvard Business School Publishing.

Elrod, P. D., II, \& Tippett, D. D. (2002). The "death valley" of change. Journal of Organisational Change Management, 15(3), 273-291.

Grow, G. O. (1991). Teaching learners to be self-directed. Adult Education Quarterly, 41(3), 125-149.

Higgs, M., \& Rowland, D. (2010). Emperors with clothes on: The role of self-awareness in developing effective change leadership. The Journal of Change Management, 10(4), 369-385.

Houle, C. (1992). The literature of adult education: A bibliographic essay. San Francisco: Jossey-Bass.

Jaros, S. (2010). Commitment to organizational change: A critical review. Journal of Change Management, 10(1), 79-108.

Kanter, R. M., Stein, B., \& Jick, T. (1992). The challenge of organizational change: How companies experience it and leaders guide it. New York: Free Press.

Knowles, M. S. (1975). Self-directed learning: A guide for learners and teachers. New York: Cambridge Book Company.

Kotter, J. P. (1995). Leading change: Why transformation efforts fail. Harvard Business Review. MarchApril. Boston: Harvard Business School Publishing.

Livneh, C. (1988). Characteristics of lifelong learners in the human service professions. Adult Education Quarterly, 38(3), 149-159. 
Maier, J. L., Clark, W.J ., \& Remington, W. S. (1998). A longitudinal study of the management information systems (MIS) job market. Journal of Computer Information Systems, 39(1), 37-41.

McMurtrey, M. E., Downey, J. P., Zeltmann, S. M., \& Friedman, W. H. (2008). Critical skill sets of entrylevel IT professionals: An empirical examination of perceptions from field personnel. Journal of Information Technology Education, 7, 101-120. Retrieved from http://www.jite.org/documents/Vol7/JITEv7p101-120McMurtrey312.pdf

Moran, J. W., \& Brightman, B. K. (2001). Leading organizational change. Career Development International, 6(2), 111-119.

Noll, C.L., \& Wilkins, M. (2002). Critical skills of IS professionals: A model for curriculum development. Journal of Information Technology Education, 1(3), 143-154. Retrieved from http://www.jite.org/documents/Vol1/v1n3p143-154.pdf

Oddi, L. F. (1987). Perspectives on self-directed learning. Adult Education Quarterly, 38(1), 21-31.

Potgieter, B. C., \& Bruce-Ferguson, P. (2003): Is there a need to assist HOD's manage change and innovation projects? New Zealand Applied Business Education Conference, 30 Sep - 2 Oct 2003.

Pratt, D. D. (1988). Andragogy as a relational construct. Adult Education Quarterly, 38(3), 160-181.

Rogers, C. (1983). Freedom to learn for the 80s. Columbus, OH: Merrill.

Srinivasan, S., Guan, J., \& Wright, A.L. (1999). A new CIS curriculum design approach for the $21^{\text {st }}$ Century. Journal of Computer Information Systems, 39(3), 99-106.

Starke, F. A., Sharma, G., Mauws, M. K., Dyck, B., \& Dass, P. (2011). Exploring archetypal change: The importance of leadership and its substitutes. Journal of Organizational Change Management, 24 (1), $29-50$.

Strebel, P. (1996). Why do employees resist change? Harvard Business Review. May-June. Boston: Harvard Business School Publishing.

Topi, H., Valacich, J. S., Wright, R. T., Kaiser, K., Nunamaker, J. F., Jr., Sipior, J. C., \& de Vreede, G. J. (2010). IS 2010: Curriculum guidelines for undergraduate degree programs in Information Systems. Communications of the Association for Information Systems, 26, Article 18. Available at: http://aisel.aisnet.org/cais/vol26/iss1/18

Trader-Leigh, K. E. (2002). Case study: Identifying resistance in managing change. Journal of Organizational Change Management, 15(2), 138-155.

Turner, R. (2004). Towards a structural model connecting hard skills, soft skills and job conditions and the IS professional: The student perspective. Issues in Informing Science and Information Technology, 1, 977-991.

Van Schoor, A. (2003). Learning to overcome resistance to change in higher education: The role of transformational intelligence in the process. HERDSA (Higher Education Research and Development Society of Australasia Inc.), 6-9 July 2003, Christchurch, New Zealand. Available at http://surveys.canterbury.ac.nz/herdsa03.

White, J., Pinnegar, S., \& Esplin, P. (2010). When learning and change collide: Examining student claims to have "learned nothing". The Journal of General Education, 59(2), 124-140. 


\section{Biography}

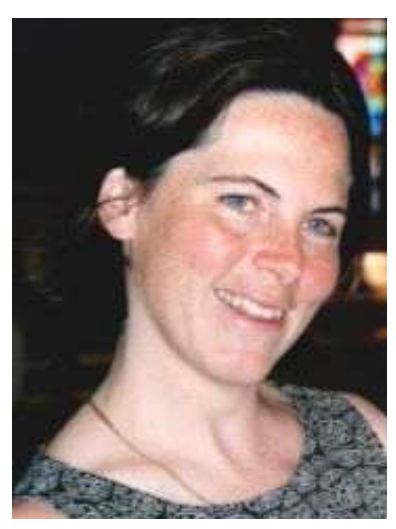

Susan Benvenuti is a lecturer in Information Systems at the University of the Witwatersrand (WITS), South Africa. A member of the IS Department at WITS since 2001, she has been lecturing for over 12 years, having worked in the IT industry for IBM prior to that. She has lived, worked and travelled in Africa, Asia, Europe and the USA. Her research interests focus largely on IT/IS Education, and in particular on teaching and assessment that facilitate transfer of learning and selfdirected lifelong learning. She is part of a multi-disciplinary, university-wide research group focusing on Assessment for Learning. 